\title{
Loaded dice: Games playing and the gendered barriers of the academy
}

\author{
Sara Ashencaen Crabtree* \& Chris Shiel
}

Professor Sara Ashencaen is Professor of Social \& Cultural Diversity in the Faculty of Health \& Social Sciences at Bournemouth University. UK.

Professor Chris Shiel is a professor in the Department of Life and Environmental Science in the same university.

Corresponding author:

Professor Sara Ashencaen Crabtree

Faculty of Health \& Social Sciences,

Bournemouth University

R206 Royal London House

Christchurch Road

Bournemouth, Dorset, UK BH1 3LT

+44(0)1202962 801; scrabtree@bournemouth.ac.uk

ORCID number 0000-0002-8479-7066 


\title{
Gender and Education
}

\section{Loaded dice: Games playing and the gendered barriers of the academy}

\begin{abstract}
This paper explores the perceptions and experiences of women academics in the UK, participating in a small-scale qualitative study exploring career progression and encountered institutional obstacles. The accounts are considered in terms of both disadvantageous institutional strategies as well as interpersonal ones governing dayto-day working relationships. The findings contribute to a growing body of international research on gender constructions in the academy, where here both inhibiting and exclusionary barriers are examined in focus group discussions in terms of gendered constructions that are perceived to impact upon the career opportunities of women academics. Analysis of data encouraged the employment of a ludic construction in this critical exploration of games playing and 'gamesmanship' (a masculinised term); these being themes raised in the focus group discussions as representing blocks and challenges to women's academic careers.
\end{abstract}

Keywords: Women academics, careers, gender, ludic, barriers

\section{Introduction}

Globally greater numbers of women are benefiting from tertiary level education than ever before (OECD 2014; HESA 2013). Mirroring the rise of female students, women academics are also found in higher education institutions (HEI) in increasing numbers. However, just as wage-earning gendered discrepancies can be found in the graduate employment market (Elias and Purcell 2013), the career pathways of women academics are viewed as strewn with obstacles (Morley 2013). O'Connor (2015) 


\section{Gender and Education}

comments that irrespective of the higher status some women may hold in the academy, gender issues remain conspicuous, where women's status stands relative to that held by more numerous male colleagues. Although the general view of academic institutional barriers is contested in a study of Australian HEIs by Probert (2005), there exists strong statistical data indicative of sexist discrimination in British academia; although the nature of these obstacles and disadvantages requires further and more nuanced interrogation.

This paper reports findings from a qualitative study focusing on gendered barriers in a university in South England but where links can be made with, and are informed by, international research. Participants were drawn from an organised collective of women scholars established at, but independent of, the existing University's structures. This collective, the 'Women's Academic Network (WAN)' is a fast growing nexus of women academics and female postgraduate students from across the Faculties. This study followed from an informal survey of WAN members in 2014 indicating that slow and obstructive academic career progression was a main source of discontent for female faculty staff.

WAN was established in 2013 to meet the perceived needs of female colleagues for an independent forum. Its primary aim is to raise the profile of women academics in the institution, advocate on their behalf over a range of gendered, workplace issues and support them in terms of career progression. A 2017 survey of WAN indicates that it continues to be seen to be important and also indirectly meets institutional key strategic aims. These include the promotion of inclusion, representation and progression of minority ethnic staff and students via the UK Equality Charter Unit and Athena Swan Awards, as well as serving the institution's equality and diversity agenda. 


\section{Gender and Education}

In this study, the term 'corporate', as applied to an HEI, may seem anomalous and indeed, possibly, a misnomer given the profile of most State-funded universities as charitable, public organisations. The term resonates with ideas of tightened surveillance over educational governance enacted in an unchecked neo-liberal globalised climate (Blackmore 2013; O’Connor, 2015). Our employment of the term openly acknowledge the distinctions of 'fit' in respect of different institutions where there are obvious differences between British HEIs, such as the elite, researchintensive Russell Group universities and teaching-intensive universities; between the nineteenth century 'red brick' universities and post-'92 institutions, of which the HEI in this study is a latter example.

Correspondingly careers are shaped within and by these institutions. Yet the position of women academics may not necessarily be so very distinct across HEI, based on the rationale offered by Bostock (2014), in examining the academic success of women scholars at the outstandingly prestigious University of Cambridge, where so-called 'meritocracy' is argued to carry in-built gender biases.

Such institutional distinctions apply across the international sector as, for example, in reference to the status differences between German Hochschulen, Fachhochschulen and Universitaet. Institutional status in turn influences recruitment, career patterns and trajectories. Arguably, therefore, if the general gendered position of women scholars is perhaps less different than might be assumed, based on the status and notion of corporate HEI, the quasi-business model is claimed to be insidiously permeating contemporary universities globally, as argued by feminist academics, Berg and Seeber (2016). Accordingly in the pseudo-corporation students become customers, academic knowledge is characteristically packaged as a commercial commodity and academics themselves (as knowledge production workers) become 


\section{Gender and Education}

subject to increasing managerial control and surveillance (Blackmore 2013; Collini 2012; Morley, 2013).

Furthermore the corporatisation of HE has notably occurred during the same period that women are entering HE in higher numbers as both students and academics (David 2015). These changes to the academy clearly carry ramifications for all academics, but particularly so for women in their precarious and negotiated entry into prestigious, male-dominated workspaces, which are also under rapid transition in relation to morphing into new types, forms and practices (Wilson et al. 2010). These changes may provide opportunities for women but may also hamper their progress. It is the latter issue that is considered in this paper in respect of corporate competitiveness and gendered impediments.

\section{Literature Review}

There is a wealth of evidence internationally regarding gender disparities in academia. Internationally there has been much focus on the so-called STEM subjects (science, technology, engineering and mathematics), most often portrayed as particularly inhospitable to women scholars, in terms of low numbers and 'leaking pipe', high attrition rates (Carr et al. 2015; 2011; Wright et al. 2003). The Athena SWAN agenda in the UK (seeking originally to promote women in science but now extended out to other disciplines) is used as a benchmark standard for HEIs; and where failure to engage in the agenda can result in HEIs being unable to successfully compete for Research Council funds, as their statement on commitment to diversity makes clear (http://www.rcuk.ac.uk/funding/diversity/). 


\section{Gender and Education}

Academia is often deemed to be a hard taskmaster, particularly where women are concerned. A term we use in this paper, masculinist working environments, refers to the conceptual notion of a 'male model of work', understood to mean compliance to a regime of almost total and uninterrupted commitment to waged work (Pascall 2012). This work model creates problematic conditions for women combining work with personal commitments (Heijstra 2015). However, Probert (2005), writing from the Australian context, argues that it is the domestic sphere and choices made therein, rather than academic policies and practices per se that create career disadvantages for women academics (Wilson et al. 2010). In this vein, high levels of stress experienced by women academics in terms of 'double shift' pressures of waged work and parenting is considered by Acker and Armenti (2004). Toffoletti and Starr (2016) explore the perceptions of women academics in Australia who deem a work-life balance to be virtually beyond reach in academia.

In reference to Denmark, work-place stress is apparently heightened where the work values of the institution conflict with those that are personally held (Opstrup and Pihi-Thingvaad 2016). Disappointed expectations of academia, lower academic salaries and generally low job satisfaction are factors implicated in the loss of women academics from the profession (Spivey et al. 2012).

The situation for British female academics offers no encouraging corrective to these international inequalities. UK HESA data reports that for the year $2013 / 4$ only $22 \%$ of professors are women, which represents a modest rise on the $15 \%$ for the year 2003 (Grove 2015). Academic wages represents another cause for serious concern where the UK University and College Union (UCU) report a 12.3\% gender wage gap disfavouring women academics for the year 2014-5; this being a marginal increase on the previous year (UCU 2016). 


\section{Gender and Education}

The competitive nature of academia is subject to both the elements of overt standards, usually framed in terms of written policy and key performance indicators, as well as more ambiguous markers of success. Policy and practice form part of the ludic construction of the workplace relating to the creation of rules of the game and the enforcement of these, which are designed to increase competitiveness and productivity between workers (Oravec 2015). The artificiality of rules in diverse human contexts that become normatively established as existing ontologies, is a notion explored in more detail by Shields (2015).

Hochschild's (1979) early work on emotion developed the concept of rules governing the fit or otherwise of feeling particular emotions in given contexts by individuals. 'Feeling rules', therefore, control not so much the actual emotion created by situations, but the expression of and sense of appropriateness to do so by the individual, according to normative beliefs and peer group pressures (Shields 2015, $551)$.

In this paper we recognise the notion of gender as a social construction, which is formed through the influences of socialisation involving identity politics, and duly enacted in daily practice (Charlebois 2011; Wharton 2012). Morley (2013) comments on the central issue of how gender is thereby constituted in the academy. In this study those 'othered', as being unlike self, were viewed by participants in gendered terms as normally men, but could include other women actors, interacting and manoeuvring for advantage in the competitive, masculinist workplace context (Oravec 2015). Gender was interpreted by participants as contingent upon perceived external ontologies (biological sex being an obvious example) (Butler 1999); but also in terms of gendered practices, which might include men taking on feminised identities or roles as well (Author's Own 2014b). 


\section{Gender and Education}

In reference to this Riviere's (1929) classic psychoanalytic formulation of the female masquerade as concealment of masculine traits as a woman's protective device against men, was inverted. Here it was reframed as the perceived rejection of womanliness by 'other' woman, who instead emulate masculinised performance openly.

Connell's (1995) concept of the 'masculine hegemony' also illustrates how the hierarchical benefits of the masculine prerogative, as dominantly wielded by 'alpha males' can also be accessed by men of lesser status by virtue of gender. Connell's analysis clarifies how women's disadvantage in the academy could therefore act as a benefit to male colleagues in terms of competition for promotion and in terms of the allocation of tasks.

The dramaturgical performance of gender and the presentation of self (Goffman 1959) implicates WAN as an entity, in being framed as a woman-centric forum. However, a later study conducted by the authors, indicated that the few women, who might be regarded as very successful by general institutional standards, were far more likely to view their success as irrelevant to their gender (Authors' Own 2017). By contrast women participants in this study were more likely to view these same successes as far less attainable on the grounds of gender; and where it was felt to be an overt obstacle to general advancement

Research activities in the UK, as elsewhere, retain their elite status and where in Britain the participation and/or recognition of women scholars remains questionable. The recent UK-wide Research Excellence Framework (REF) 2014 demonstrated firstly, the low inclusion of women academics across disciplines (along with minority ethnic academics) (Matthews 2015); and secondly, the unequal gender selection of 


\section{Gender and Education}

academics for inclusion in the REF (HEFCE 2015). Commensurately both O'Connor (2015: 311) and Grove (2013) sardonically refer to the 'administration of teaching' as the primary academic role of many women and thus the 'new housework'.

Teaching and learning roles are part of the myriad of time-consuming faculty chores largely undertaken by women and additionally relate to the management of teaching programmes and student/pastoral issues, where nurturance and care in the academy seems automatically associated with women (Mariskind 2014). These, as well as other maintenance and nurturing roles, fall under the notion of emotional labour (Hochschild 1983, 2003; Eddy and Ward 2015). In this context emotional labour is a short-hand for work regarded as vital to corporate functioning, while ensuring that casualty rates among students and staff are kept as low as possible.

Although there is comparatively little in the research corpus referring to emotional labour in academia (Darby 2017), Lester (2008) comments on women's greater participation in faculty chores as the 'glue work' of so-called 'academic citizenship'; which being largely unrecognised and unrewarded create the risk of leaving women academics feeling frustrated, cheated and unfulfilled. Equally, although essential to smooth operations, Tunguz (2016), in reference to the USA, notes a higher level of emotional labour in academics who are low in power (i.e. in insecure academic employment) as opposed to tenured staff; also commenting on the lack of corporate recognition that makes 'emotional labour' unrewarding in any material sense. The gendered element of such work echoes the unsung mothering drudgery that students and corporations tend to expect from women staff as compatible with their gendered identity and socially constructed normative roles (Guy and Newman 2004); and where female deviance in the form of refusal to accommodate these expectations is criticised. 


\section{Gender and Education}

The position of women in UK colleges of Further Education (rather than tertiary level HEI) is considered by Leathwood (2005), but despite institutional status and purpose, useful comparisons can be drawn in terms of surveillance and control of educators, manifested in managerial bureaucratised approaches pervading education. Leathwood (2005) argues that while the opposite is claimed, a managerial rationale operates to deskill educators, where the discourse of so-called 'professionalism' is used to construct, define, limit and shape the role and identity of the educator as subsumed in the corporate body. Through the processes of isomorphic convergence such discourses have entered corporate global academia, in terms of increased layers of bureaucracy and managerialism associated with 'top-down' control mechanisms (Berg and Seeber 2016; Morley, 2013; Wilson et al. 2010)

While there is a considerable body of feminist research into the harassment of women in the workplace, there is scant data on workplace bullying implicating women who harass others (MacIntosh et al. 2015), although notably this was a reported finding here. Skelton (2005) explores the issue of interpersonal, gendered tensions in academia where the troublesome feminist issue of women exerting power over other women raises its head. In the corporate, contemporary university, where women are slowly gaining a purchase on the vertical glass wall, individual strategies to pursue career advantage can implicate women in oppressive tactics against others.

Using a gendered 'conversational' analysis, Hale (1999) considers the perception of female and male academics (and administrators) in terms of exclusion from power and how these gendered dynamics play out in the working environment. In the masculinist university context, emotion may be viewed negatively as reducing staff credibility (see Lester 2008). In accordance with Hochschild's (1979) point regarding 'feeling rules', Hale argues that expressed emotion is viewed as devalued and 


\section{Gender and Education}

devaluing in terms of visible distress (an apparent womanly weakness, rather than maybe those emotions conventionally associated with masculinity).

In this respect Williams et al. (2016) explore aggression (as manifested in various ways) with the conjecture that low-power individuals are more likely to seek power over others. It is claimed that these individuals are motivated to avidly pursue power for its own sake, 'as an attractive, long-awaited opportunity to bolster their own control over others' (Williams et al. 2016, 3). The issue of low power clearly carries implications for marginalised groups, in terms of gender, ethnicity and class. Hale (1999) quotes from a male academic participant who claims that male aggression in the workplace is a game of dominance with specific masculine rules of engagement, but one that women, with their historical disenfranchisement do not fully understand; and are in consequence may be viewed as more dangerous and unpredictable given the chance to engage in power games.

A deeper understanding of the role of play moves us beyond that of rule observance into the territory of psychoanalysis. For the renowned psychotherapist, Winnicott (1971), play is a human universal. Its main function in early life specifically relates to the evolving relationship of the 'good enough mother' and her baby through the infant's attachment to transitional objects. The infant may be frightened by its play at times, and therefore play needs to be managed by benevolent adults. Nonetheless for Winnicott (1971) play is overwhelmingly positive, of itself therapeutic and holding powerful properties of authenticity, where the search for self can take place through play's crucial element of immersion into creativeness. In response to Winnicott, André Green (2005) offers a darker interpretation, where play can relate to, not solely health, but also human sickness. As we may remember from the playground, not all games are kind, developmental or sustaining. Some are embedded in the need for 


\section{Gender and Education}

dominance and submission where players seek 'to harm, debase and destroy the other' (Green 2005, 11). These contrasting psychoanalytic views of play resonate with the findings of Hale's study with its discourse of male-type, wholesome, competitive, rule-bound sport versus perceptions of women's play as opportunistic, cruel and excessive.

The strategic games playing of individuals in the workplace apart, countering female privilege among males through the mentoring of female academics by other women, may act as a crucial support mechanism. A decade has passed since Schor (1997) noted that female academics with mentors publish more articles, feel more confident, and are more satisfied overall with their careers than those without mentors. Mentorship itself can be regarded as a novice's guide to understanding the rules of academic ludo and teaching others how to 'play the game' (Ali and Coate 2013, 24; Morley 2013). However, although this may achieve the desired result of promoting individual advancement, this may come at the cost of acquiring new forms of selfgovernance and self-presentation as part of these enhanced rules of engagement (Goffman1959; Hochschield 1973).

Commensurately, the notion of mentorship needs to be tailored to individual circumstances, as argued by Blood et al. (2012), and does not, of itself, overcome the potential danger of oppressive hierarchical differentials between women colleagues. McGuire and Reger (2003) offer the notion of feminist 'co-mentoring' in which the dualism of object and subject, mind and emotion, seemingly promoted in masculinised practices in academia, are deconstructed as part of the feminist mission. By acknowledging the emotive as informative opportunities for learning about and overcoming problems in peer support the authors argue that co-mentoring, 


\section{Gender and Education}

(draws) on feminist principles, co-mentoring redefines emotion as a source of knowledge and a catalyst for understanding, rather than a distraction from one's academic development (McGuire and Reger 2003: 55)

Ultimately negotiating perceived male-dominated workplaces as a woman brings both an awareness of gendered anomalies, impediments, but also invitations to resort to different strategies (Lester 2008). Adopting gendered camouflage by disavowing the female is one such strategy, serving to confirm that the normative space does indeed belong to the male. Other strategies (Addison 2014) are to play upon the perceived discrepancies of being a female in a male context to elicit male chivalrous, paternalistic favouritism or tokenist privileges. Alternative strategies may direct individuals towards particular dress, language and emotional affect to convey a particular positionality in the workplace situation (Lester 2008) - but in each case the question of gender is brought to the fore (Gill et al. 2008). It is these oppressive gendered practices and attitudes, identified by participants as forms of gamesmanship, a term used consciously in respect of the gendered aspect of games playing and oneupmanship, that will be explored further in this paper.

\section{Methodology and methods}

This small-scale study was originally informed by an earlier WAN survey exploring members' perceptions on a range of issues in the workplace. WAN does not specifically label itself as a feminist network, as it encompasses a range of views and positions among its female members, although in practice it operates as such. Here we seek to subvert researcher-subject hierarchies, which conforms to our feminist principles. In so doing we argue that this acknowledges a feminist consciousness of 


\section{Gender and Education}

sexist oppression, implicating female researchers, explored through reflection and self-reflexivity (Stanley and Wise 1994; Author's Own 2016); and where we, in turn, research our own condition. Finally, the study attempts to create new levels of consciousness through the co-construction of knowledge by participants and researchers.

A range of voluntary participants from WAN were recruited for the study, which employed focus group discussions to explore three main research questions:

1. What barriers to progression do women academics within the institution experience during their careers?

2. How are the implications and impact of these perceived?

3. How do participants identify positive solutions that might facilitate change based on these experiences?

Focus group discussions (FGD) were chosen as the preferred method of data gathering, enabling participant perceptions to be explored through group dialogue, allowing views to be elicited via facilitation. As a methodology the fundamental dialogical element of FGD permits topics to be explored in depth and serves to generate deeper insights through participation in the discussion. Individual contributions from every participant in FGD interviews were invited, noted and recorded rather than subsumed into the wider discussion (Seal et al. 1998). Consensus is not regarded as the aim of FGD, but rather the context and content of what participants offer to the topic are treated as raw data (Bryman 2016; Woodyatt et al. 2016).

Although there were many differing individual views offered by participants, it was interesting to see how much convergence there was on particular topics relating to 


\section{Gender and Education}

perceived gendered barriers. That said, this paper also offers some divergent views from members serving to illuminate the complexities of perceptions relating to, for example, individual career trajectories and mentorship. These serve to foreground the collective experiences of gendered disadvantage as explored in the group.

In terms of analysis the raw data from FGD was subjected to coding at various levels of complexity in which the emerging themes form the findings of the study (Author's Own 2011). These have been further developed as clustered within the conception of ludos as a meta-discourse. Each of the six overarching themes forming the findings of this study were vertically developed through three layers of coding serving to refine the data. For example, themes refer to how the voices and position of male colleagues are privileged over and above those of female colleagues. These are supported by codes relating to examples of differing gender expectations of academic roles, as well as examples relating to differing access to opportunities and resources. These serve to supporting the first tier of coding referring to the consequent greater likelihood of male career advancement compared to most women colleagues.

Another example refers to the theme of 'tokenism', as a strategy of female gamesmanship, such as the adoption of or identification with masculine traits. The consequent disavowal of the perceived and constructed notion of the female, together with coding relating to specific examples relating to the maintenance of uniqueness by reducing female competition, leads to 'tokenism'.

Codes collated within the themes reflect phenomena relating to individual strategic career positions, indicating gamesmanship and channelling strategies within Faculties, these refer to communication or role allocation. Identity politics emerged strongly as a 


\section{Gender and Education}

finding in how female colleagues portray themselves, resonant of the notion of Riviere's (1929) masquerade.

In terms of methods the data-gathering element took place over four months where 58 participants were sought for 3 group discussions and where selected findings discussed here were drawn from each FGD. While all WAN members were contacted to participate via group email lists, other potentially eligible participants were invited via institutional intranet group communication.

For FGD it is generally considered important for a level of commonality (however this may be defined) to exist between participants to ensure that topics are relevant to participant groups. Commonalities here encompassed gender, profession and institutional employment, with academic participants positioned across employment academic scales; although the majority occupied levels below that of Principal Lecturer (this status roughly corresponds to a point between Associate and Assistant Professor in this particular HEI).

Other variation related to discipline areas where participants were invited from the four faculties covering the discipline areas of media, humanities, social sciences, nursing, public health, conservation and natural sciences, technology, business, tourism and sports sciences among other interdisciplinary groupings.

Participants represented a wide age range, from young academics in their thirties to older academics approaching retirement. All participants were permanently employed and where the majority worked full-time. Participants were drawn from junior lecturers to two full professors, although the majority held positions below that of Associate Professor. This is consistent with the gendered cluster effect where there are disproportionately lower numbers of women occupying the higher university 
ranks (Morley 2013). Although identified as an important dynamic in understanding the changing position of women in academia (David, 2013), the complexities of class were not discussed in any depth in the FGD. Yet because seemingly few participants had originally expected to become university academics, the goal carried an aura of the serendipitous rather than that of entitlement.

The researchers' employing institution holds an international academic staff group and accordingly the study attracted a large minority of non-White British participants. Overall participants included White Britons, Northern and Southern Europeans, East Asian/Asia-Pacific rim (including Australasia), South African, North and South American colleagues. No Black British participants were recruited for reasons unknown; although such academics form a conspicuous minority at the University, which is openly recognised as an issue of concern under its dignity and diversity agenda. Sexual orientation was not discussed in the FGD, although work-life balance problems raised problems concerning meeting personal commitments in professional, masculine work contexts.

Finally, instead of anonymous signifiers we have chosen to use fictional names in reference to individual accounts, as part of our feminist commitment to avoid the objectification of participants.

\section{Ethical considerations}

All conventional ethical protocols were observed as mandated by the University Research Ethical Committees in respect to confidentiality, the right to withdraw from participation and data protection considerations. Although ultimately the volunteers and the researchers were all WAN members there was no coercion applied in respect 


\section{Gender and Education}

of WAN membership and no compromise to working relationships for declining to participate.

Emotional support was made available to participants in the event of potential distress arising from the FGD. However, none chose to access this support but instead it was found that participants expressed great relief at being able to discuss their experiences and their feelings in the confiding and safe environment among known WAN members.

\section{Findings}

Thematic analysis of data revealed themes concerning participants' perception of gendered channelling down particular academic routes and into certain kinds of academic roles. Some participants viewed these as providing an advantage to particular individuals, but the majority opinion regarded this divergent route as handicapping in the academic career game of snakes-and-ladders, as articulated by one individual.

Roz: 'I appreciate everything you have said about how the rules change. One minute it looks like we're on a hockey pitch, the next minute the game's changed to tennis, but we've still got hockey - that's what it feels like.'

Institutional capriciousness regarding the rules for engagement at the HEI was expressed by this participant as part of a dominant discourse among participants relating to gamesmanship. Thus, although rules of the game were generally understood by most players (with novices duly initiated into these), yet there was a general recognition in each FGD of how other unnamed colleagues ignored or subverted academic 'rules'. Rewriting and discarding of rules, conforms to an extent 
with Winnicott's (1971) understanding of creative play, yet the effect on others, was more akin to Green's (2005) position regarding play as also concerning dominance in its ability to undermine the position of others. Internal conflict was experienced by several participants by seeing certain colleagues 'cheating' with apparent impunity. It undermined notions of fairness (a quality associated with sportsmanship), particularly where participants felt institutional rules should serve legitimate functions of forging established and shared understandings of academia.

\section{The game of 'getting ahead and staying ahead'}

Seeking to gain a competitive edge in academia is (to pursue the metaphor) a long established game, and one where artificial competition across institutions is heightened through the deliberately divisive, government-devised strategy of the REF (Kelly 2016). Within institutions the general issue of what kind and levels of academic work is allocated to whom adds to a sense of potential inequities - and where participants in this study appeared to view themselves as frequently disadvantaged in terms of workload - and often owing to their gender (Morley 2013; Lester 2008). In this vein O'Connor $(2015,310)$ notes the 'chilly' organisational culture of academia revolving around male lifestyles and priorities.

References were made by participants concerning the intensity of work at the institution, often experienced as a masculinised work culture of total immersion (Pascall 2012; Wilson et al. 2010). While to an extent this was recognised as typifying academic organisational culture, alternative approaches to undertaking productive work were felt to attract little credibility. For example, while 'slow' scholarship strategies may stake important feminist claims for academia (Berg and Seeber 2016), the confluence of established hegemonic, masculinist discourses in alliance with 


\section{Gender and Education}

contemporary neo-liberalist, corporate agendas, provide inhospitable ground for gaining a foothold.

Some participants regarded themselves as not only lowly in rank but as naively ill equipped to level out the playing field owing to the cannier strategies and devices they saw played out around them.

Carla: Yes, I'm a demonstrator. There are 5 male colleagues among the 30 odd demonstrators here...who on the outside portals, like Linked-in, they write 'lecturer' in. And I was really surprised by this because I always feared that I would have to explain to the outside world that I'm also lecturing, whereas they just don't care. Which means what? If they apply for a job and I apply for another job, would they have better chances because they've been saying that?

How others self-present (Goffman 1959) generates for this speaker the disillusioning notion that dishonesty might well pay rewarding dividends. It is interesting to note that this creative strategy was portrayed by the participant as associated with being a male game. This was suggestive in underlining key gender differences that create unequal career terrain: an essentialised notion of bold opportunism in men versus timid (but possibly envious) scrupulousness in women.

Effective self-aggrandisement not only boosts internal egos and the external kudos of individuals but also carries ramifications in terms of how quickly someone may be able to scale the career ladder in consequence. The allocation of lower status work, normally that relating to 'emotional labour', such as taught programme management, care of students, informal mentoring and academic citizenship, needs to be divided among staff left over (or left out) from loftier paths (Eddy and Ward 2015; Mariskind 


\section{Gender and Education}

2014; Grove 2013; Lester 2008). However, such roles rarely lead to rapid advancement and can be highly detrimental to female colleagues' ambitions, acting as a further disincentive.

In respect of the research question on identifying positive solutions to barriers, the issue of mentoring and sponsorship was raised. Fortunately not all participants in the study had experienced sexist discrimination in academy, although admittedly these were a very small minority, where Jo's account below forms one of the divergent views emerging from the FGD.

Jo: I was taught by these very old [male] professors ... Everybody thought, especially in archaeology, that it would be very male orientated and that women should really just do a degree and become a wife. But I had very positive experiences all my life in very competitive sectors... And I have to say, until very recently, I never had a bad experience personally with a male superior, or professor or supervisor. It turned out if you're a good student it didn't matter whether you were a man or a woman - he would sponsor you.

The distancing of self from the wider question of gender in the academy offered an alternative and minority view (Author 2017). In this account the message is that gender neutrality is evident in academia and that career advancement through individual sponsoring can be invaluable. Except that the subtext indicates that the advantages of sponsorship are offered by established male professors. These are the patriarchs of the discipline, who in themselves hold great power to promote or undermine the careers of junior staff; and where apparent promise may be discernable via criteria, codes, initiation or presentation that is likely to be written by dominant groups who maintain the status quo. These may include a few 'elite' women, as 
referred to by O'Connor (2015), but nonetheless they sremain marginal figures

numerically and in terms of the greater influence they can bring to changing academic cultures.

Benevolent influence was more likely to be felt at very localised levels in respect of the kind of mentoring made available to women academics (Blood et al. 2012). Here the key issue of timing appears all-important in determining the efficacy of active mentorship.

Petra: I have a colleague in another faculty who has taken me under her wing for the last couple of years...I guess she saw something in me...she gives me advice and then sends me things, 'go apply for this, do that' - and I never have the time to do it. And I feel every time I communicate with her I feel I am letting her down in some way because she's putting this time and energy into me.

If appropriate mentoring comes during the early career years as it did for 'Jo' then there is the chance to avoid being pigeonholed into mundane, low status academic tasks. If this has already come to pass, as in 'Petra's' example, it can be a case of diminishing returns where the mentee finds it much harder to gain benefits from the assistance given, because the die is effectively already cast.

\section{'Queen takes all' -gendered power games}

The workplace context is the stage where dramas of enacted power are played out. Emerging from the margins of metanarratives, feminism springs from this postmodernist fracturing and serves to deconstruct the concept of power as centrally 


\section{Gender and Education}

located. Instead power is viewed as dispersed among players and thus decentralised meaning it is also potentially harder to identify and tackle (Author's Own 2014a).

Feminism has struggled with the issue of power exercised by women upon others in its less benign forms (MacIntosh, et al. 2015; Skelton 2005). It is in reference to this troubling terrain that participants discussed their experiences of first- and secondhand of obstacles raised against them specifically as women academics in the threat they posed towards colonising perceived male spaces (Hale 1999). In reference to the authority of elite women in organisations, one participant remarked:

Sue: Margaret Thatcher characters - the kind of women who've risen very quickly and highly in a particular organisation, who will kind of trample on women below them so that they maintain their position of uniqueness. And that was something which was described to me by a lot of colleagues...

The privilege of uniqueness in terms of female success (which here we choose to define conventionally in terms of rank and payroll), practised in masculinised working environments can lead to harassment of elite women (McLaughlin et al. 2012); but in turn, female success may not, as a matter of course, ease the path of fellow women. This is likely to be particularly so if such tokenism is viewed by the incumbent as a useful strategy that has enabled them to rise from the undistinguished and uncelebrated female masses to acquire power as opportunity, rather than power as responsibility (Williams et al. 2016). Here too enacted female sexism towards other women appears to retain the power base of such individuals, in which forging alliances with the prevailing power base serves individual interests (Gill et al. 2008), but which in turn may harm the wider interests of groups. 


\section{Gender and Education}

Louise: I've had odd experiences over the years but particularly in the faculty now.

My experience, has been more about the way that senior women treat senior men more differently to other women, in terms of opportunities and access and listening ...In my experience they privilege the male voice above the female voice.

The power of line management, particularly in the corporate workplace with its multiple layers of organisational functionaries (Berg and Seeber 2016), is a hierarchical, military-style 'command-and-control' structure that can leave employees in clearly vulnerable positions (Leathwood 2005; Wilson et al. 2010); particularly if decisions are made that are felt to be coloured by bias.

Olivia: I think it's all about not being listened to, especially when what you say doesn't agree with what they want to do... And that is, as I say, not just from, predominantly from the men's point of view, but also in a few cases, I've had a few nervous breakdowns because of you know, a woman making decisions with a colleague, a male colleague, about me and my workload, or whatever.

It is notable that gendered dynamics where one manager is a woman, as referred to in 'Olivia's account, appears to carry such destructive weight. This point is further illuminated in a response to this comment from another participant with a confirmatory point regarding the complicity in undermining the position of fellow women.

Marta: I feel this! I can absolutely support that, because it feels even worse if it's women who undermine what you do. And especially when they get into certain higher positions - suddenly turn into what? But they start to bite, so to say, in terms of, you know, they were in the same position years earlier, but 


\section{Gender and Education}

then they get in a certain position - whether it be administrative or academic and suddenly there is no support anymore, although you think, 'you should understand this, you came from the same position!'

An easy assumption of gendered solidarity, forged through the commonalities of shared experiences, is no guarantee in the workplace for women colleagues. It would appear that the expectation of gendered support of woman to woman that is assumed and subsequently disappointed carries a far greater sense of betrayal than would otherwise be felt in dealings with male seniors only, who could perhaps be dismissed as typically sexist, just obtuse or incompetent.

Keeping bad faith with the academy's foot soldiers is the topic of the next participant account:

Moi: I think that there's a lot of loop holes and I think line managers are beating to a completely different drum....line managers communicate one thing to their staff that their managing and then I think they're communicating something completely different to I think that there's a lot of loop holes and I think line managers are beating to a completely different drum ... I think they're communicating something completely different to the UET (University Executive Team). Yeah, probably I'll be shot for saying this, I don't UET are always the bad guys.

This somewhat sheepish final point, rehearses the traditional dynamics of the tension and suspicion of competing agendas played out between polarised groups: the 'management/worker', 'officers/men', 'upstairs/downstairs'. Yet given that so few women achieve the higher hierarchical ranks in the academy, the implication in 'Moi's' account is that university leaders who are in the greatest majority men, are so 


\section{Gender and Education}

unreachably remote that they appear to have little understanding of what is done in their name down the chain, where far more women academics are located. The narratives suggest that because these offending others often are women they should know better in their dealings with female colleagues; whereas no such heavy burden of expectation is extended towards male colleagues blinkered by greater privilege.

A deeper level of analysis regarding the complicity of power exercised within groups of traditionally low-power lies beyond the scope of this paper. However, the issue of tokenism implies that increased numbers of higher ranking women would threaten to undermine oppressive tactics towards women by women, viewed as holding a vested interest in maintaining prodigal privileged status. Furthermore, by extension this would suggest that giving up tokenist privileges would mean that at least in the short term this is unlikely to occur. The potentially misogynistic discourse of "women beware women', as implying intense gendered competition among women academics, should certainly not be dismissed out of hand, but needs to be understood within the unequal gendered structuring of institutions. Perhaps this is particularly so, if a legacy of sponsorship of women by women has yet to be established, whether via individuals and internal support bodies like WAN.

\section{Feeling the affect - ludicrous emotion}

Goffman's (1961) famous formulation of the 'total institution' describes an environment - monastic, regimented or forcibly confined, which contains the modes of ubiquitous life: work, physical needs and leisure. Here we adopt the notion of the total masculine, hegemonic workplace (Connell 1995; Pascall 2012), of which academia is an example, an environment that not only governs the intense tempo of work but also seeks to control the emotional expression of its workforce. 


\section{Gender and Education}

Emotions are subject to moral evaluation, particularly if those expressed are not viewed as compatible with the institutional values and milieu. Work-related stress is noted to be high in academia (Acker and Armenti 2004); and where women, in relation to double shift work, bear the brunt. In one sense, managing academic workloads can never be truly mastered by the very nature of continuing aspirational, scholarly endeavour. However, in another, and very tangible sense, the expansion of higher education, along with target-driven key performance indicators, in combination with higher bureaucratisation and control of academic life (Berg and Seeber 2016), combine to create a highly stressful working environment for many. It is perhaps unsurprising therefore that expressed emotion is both a natural consequence of these workplace pressures as well as being felt to be unacceptable in the working environment. This stands in keeping with Hale's (1999) observation of compromised female credibility and the disciplined observation of rules governing emotions (Hochschild 1979).

Siobhan: I think there's something around strength too. I mean I have to say that there are days when I just want to burst into tears in my office because things have gotten too much... that's only happened once and the shame I felt because it happened in front of a male colleague. I was just mortified. But I do try to definitely put on this front that, you know, that 'yep, no everything's OK, I can handle anything, no problem'. But the number of times I actually go home and just cry because I can't handle the stress of it.

The issue of how individuals express and present themselves in the workplace is rife with gendered implications concerning those behaviours and attitudes that are validated those and those which are not. Emulation of legitimised expressions by male 


\section{Gender and Education}

colleagues may be viewed as an ill fit in women, as this exchange by three participants in one FGD suggests:

Kathy: I think, I always defined some colleagues (as) 'prima donna,' because whatever they do seems like they discovered, I don't know, you know, the secret of life.

Dani: I think there are a few women definitely (who do so) but I think it is more of a male trait.

Jo: But isn't the problem that there's women who are like that (but they) get slashed down much more than men would?

Dani: It's definitely the same traits (that) in a man are pure, sort of: you know, he's strong and he's assertive, and he's whatever. When it's a woman, it's bitchy, she has a bad character and she's not sweet.

Ironically therefore, given the gendered term, colloquially acting the prima donna is viewed as an egocentric and fundamentally unlikeable role, but participants regard this as either naturally sitting better on men than on women; or is perhaps more likely to be tolerated in men. This final account returns us full circle to the issue of disavowal of traits associated with the female, particularly in terms of expressed emotion (Riviere 1929) and what is considered appropriate to the context (Hochschild 1979).

Petra: I've had some awful experience where you come out and you feel physically sick. But I've watched other women having worst experiences, just you know, where you go to meetings and somebody's obviously really distressed and no one takes any notice of it, you know. And even the other women around the 


\section{Gender and Education}

table, you know that everyone's conscious that this person's really distressed but they won't acknowledge it. No one does anyway so I, you know... that really shocked me but I think it is also a cultural things - medically dominated.

The inference that 'Petra' makes concerning the academic medical discipline to which she belongs, as one lacking in empathy and compassion, is an example of the disorientating discrepancy of values that Opstrup and Pihi-Thinvaad (2016) refer to. However, it also raises the question of whether it is the association of stereotyped female emotion: distress, expressed by a woman in a traditionally positivist and male dominated work culture, that permits witnesses to behave in ways that are viewed as callous. It could also be interpreted as a conscious adoption of masquerading gender camouflage, since to remain coldly unmoved in the face of distress would intuitively seem unnatural and forced.

\section{Conclusion}

Based on the findings of this small-scale study, examples of negotiating male spaces as women, magnifies participant perceptions of the ubiquity of small but continual violences women experience of games-playing in the academy (MacIntosh et al. 2015). Accordingly the study focused on participant perceptions of gendered barriers to their carer progression, where this paper examines some strategies that are perceived by participants to hamper women's academic careers. Such issues relate to interpersonal interactions that harm the prospects or work patterns of individuals or are otherwise hierarchical obstacles thrown up that may threaten to obstruct or derail carer advancement. These perceptions are explored in terms of ludic constructions in respect of how games of competition are designed and enacted to gain a personal 


\section{Gender and Education}

advantage over other; as well as reviewing those games that relate to seeking privilege through the rarity bestowed by tokenism. The snakes-and-ladders gamesmanship of encountering, negotiating or being halted by obstacles may conform to or conflict with essentialised notions of gender, but where, as statistics reveal, the odds of success are significantly stacked against academic women. 


\section{Gender and Education}

\section{References}

Acker, S., and Armenti, C. 2004. "Sleepless in academia." Gender and Education 16, no. $1: 3-24$.

Ali, S., and Coate, K. 2013. "Impeccable advice: supporting women academics through supervision and mentoring." Gender \& Education 25(1): 23-36. doi http://dx.doi.org/10.1080/09540253.2012.742219

Author's Own. 2017. BU.

Author's Own. 2016. Policy Press.

Author's Own. 2014a. Religion \& Gender.

Author's Own. 2014b. British Journal of Social Work

Author's Own. 2011. European Journal of Social Work

Addison, M.T. 2014. 'Knowing how to 'play the game' at work: A study of class, gender and emotion work in Higher Education.” PhD diss., University of Newcastle Upon Tyne.

Berg, M., and Seeber, B.K., 2016. The Slow Professor: Challenging the culture of speed in the Academy. Toronto: University of Toronto Press.

Blackmore, J. (2014) "Passion, professionalism and performativity: Gender and social injustice in education.” Redress, 22(3): 49-57. 


\section{Gender and Education}

Blood, E.A., Ullrich, N.J., Hirshfeld-Becker, D.R., Warfield, C.A., and Jean Emans, S.J.

2012. "Academic women faculty: Are they finding the mentoring they need?" Journal of Women's Health 21(11): 1201-1208.

Bostock, J. (2014) The Meaning of Success: Insights from Women at Cambridge. Cambs: Cambridge University Press.

Bryman, A. 2016. Social Research Methods. Oxford: Oxford University Press.

Butler, J. 1999, 2014. Gender Trouble. New York/London: Routledge.

Carr, P.L., Gunn, C.M., Kaplan, S.A., Raj, A., and Freund, K.M. 2015. “Inadequate

Progress for Women in Academic Medicine: Findings from the National Faculty Study." Journal of Women's Health, 24 (3): 190-199

Charlebois, J. 2011. Gender and the Construction of Hegemonic and Oppositional Femininities. Maryland: Lexington Books.

Collini, S., 2012. What are Universities For? London: Penguin,

Connell, R.W. 1995. Masculinities. Cambridge: Polity Press.

Darby, F., 2017. “'Are you listening to how I look?’ Reflections on the Role of Emotional and Aesthetic Labour in Higher Education." All Ireland Journal of Teaching and Learning in Higher Education, (AISHE-J) 9(1): 2822-2827.

David, M.E. (2015) “Gender \& Education Association: A case study in feminist education?" Gender \& Education 27(7): 928-946. 


\section{Gender and Education}

Eddy, P.L, and Ward, K. 2015. "Lean in or lean out: Career pathways of academic women." Change March/April 2015: 6-12.

Elias, P., and Purcell, K. 2013. "The earnings of graduates: Reviewing the evidence from Futuretack.” Working Paper 6. Institute for Employment Research, University of Warwick.

http://www2.warwick.ac.uk/fac/soc/ier/futuretrack/findings/futuretrack_working_pap er_6.pdf (accessed November 20, 2014).

Green, A. (2005) Play and Reflection in Donald Winnicott's Writings. London: Karnac/The Winnicott Clinic of Psychotherapy.

Gill, J., Mills, J. Franzway, S., and Sharp, R. 2008. “'Oh you must be very clever!' High-achieving women, professional power and the ongoing negotiation of workplace identity." Gender and Education, 20(3): 223-236.

Goffman, E. (1961, 1991) Asylums: essays on the social situation of mental patients and other inmates. London: Penguin Books.

Goffman, E. 1959, 1990. The Presentation of Self in Everyday Life. London: Penguin.

Grove, J. 2013. "Why are there so few female vice-chancellors?" Times Higher Education. 22 August 2013. http://www.timeshighereducation.co.uk/features/whyare-there-so-few-female-vice-chancellors/2006576.article (accessed November 11, 2014).

Guy, M.E., and Newman, M.A. 2004. Women's jobs, men's jobs: Sexual segregation and emotional labor. Public Administration Review, 64, no. 3, 289-298.

Hale, M. 1999. "He says, she says: Gender and work life." Gender and Public Administration, 59(5): 410-424. 
Higher Education Funding Council for England (HEFCE). 2015. "An analysis of staff selection for REF 2014.”

http://www.hefce.ac.uk/news/newsarchive/2015/Name,104986,en.html (accessed November 10 2016)

Heijstra, T.H., Thoroddur, B., and Gudbjörg, L.R. 2015. "Predictors of gender inequalities in the rank of full professor." Scandinavian Journal of Educational Research, 59(2): 214-230.

HESA (2013) “Introduction: Students 2012-2013.”

https://www.hesa.ac.uk/intros/stuintro1213 (accessed July 10 2016)

Hochschild, A.R., 1983, 2003. The Managed Heart: The commercialization of human feeling. Berkeley: University of California Press.

Hochschild, A.R., 1979. Emotion Work, Feeling Rules, and Social Structure. The American Journal of Sociology, 85(3) 551-575

Leathwood, C. 2005. “'Treat me as a human being - don't look at me as a woman': Femininities and professional identities in further education." Gender \& Education, 17(4): 387-409.

Lester, J. 2008. "Performing gender in the workplace: Gender socialization power, and identity among women faculty members." Community College Review 35(4): 277-305.

Mariskind, C. (2014) “Teachers' care in higher education: Contesting gendered constructions." Gender \& Education, 306-320. 


\section{Gender and Education}

Morley, L. 2013. "The rules of the game: Women and the leaderist turn in Higher

Education." Gender and Education 25(1): 116-131.

MacIntosh, J., Wuest, J., Ford-Gilboe, J., and Varcoe, M. 2015. "Cumulative effects of multiple forms of violence and abuse on Women." Violence \& Victims 30(3): 502521.

McGuire, G.M., and Reger, J. 2003. "Feminist co-mentoring: A model for academic professional development." National Women's Studies Association (NWSA) Journal 15(1): 54-72.

O’Connor, P. (2015) “Good jobs - but places for women?” Gender \& Education 27(3): 304-319.

OECD (2014). “Education at a Glance: OECD Indicators.” http://www.opedu.eu/media/bibliografia/2014-OECD-Education-Glance.pdf (accessed June 8, 2016) Opstrup, N., and Pihi-Thingvad, S. 2016. "Stressing academia? Stress-as-offence-toself at Danish Universities." Journal of Higher Education Policy and Management, 38(1) http://dx.doi.org/10.1080/1360080X.2015.1126895

Oravec, J.A. 2015. "Gamification and multigamification in the workplace: Expanding the ludic dimensions of work and challenging the work/play dichotomy." Cyberpsychology: Journal of Psychosocial Research on Cyberspace, 9(3)6. doi 10.5817/CP2015-3-6.

Pascall, G., 2012. Gender Equality in the Welfare State. Bristol: Policy Press.

Probert, B., 2005. “'I Just Couldn’t Fit It In': Gender and unequal outcomes in academic careers." Gender, Work and Organization, 12(1): 51-72. 


\section{Gender and Education}

Riviere, J. 1929. “Womanliness as masquerade.” The International Journal of Psychoanalysis (JPA) 10: 303-313.

Schor, S. 1997. "Separate and unequal: The nature of women's and men's careerbuilding relationships.” Business Horizons 40(5): 51-58.

Seal, D.W., Bogart, L.M., and Ehrhardt, A.A. 1998. "Small group dynamics: The utility of focus group discussions as a research method." Group Dynamics: Theory, Research, and Practice, 2(4): 253-266.

Shields, R. 2015. "Ludic ontology.” American Journal of Play, 7(3): 298-321.

Skelton, C. 2005. 'The 'individualized' (woman) in the academy: Ulrich Beck, gender and power." Gender and Education 17(3):319-332.

Stanley, L., and Wise, S. 1994. Breaking Out Again: Feministic ontology and epistemology. New York: Routledge.

Spivey, C.A., Billheimer, D., Schlesselman, L.S., Flowers, S.K., Hammer, D., Engle, J.P., Nappy, J.M. et al. 2012. "Multi-instıtutional study of women and underrepresented minority faculty members in academic pharmacy." American Journal of Pharmaceutical Education 76(1): 1-13.

Toffoletti, K., and Starr, K. 2016. "Women academics and work-life balance: gendered discourses of work and care.” Gender, Work \& Organization 23(5). doi:10.1111/gwao.12133.

Tunguz, S. 2016. "In the eye of the beholder: emotional labor in academia varies with tenure and gender." Studies in Higher Education, 41(1): 3-20. 


\section{Gender and Education}

University and College Union (2016) "The gender paygap in higher education, 2015-

6 Data Report.” UCU https://www.ucu.org.uk/media/8620/The-gender-pay-gap-in-

higher-education-201516---full-report-May-17/pdf/ucu_2015-

16genderpaygapreort full may17.pdf (accessed July 19, 2017)

Wharton, A.S., 2012. The Sociology of Gender. Chichester: Wiley-Blackwell.

Williams, M.J., Gruenfeld, D.H., and Guillory, L.E. 2016. "Sexual aggression when power is new: Effects of acute high power on chronically low-power individuals." Journal of Personality and Social Psychology. doi: 10.1037/pspi0000068

Wilson, J.Z., Marks, G., Noone, L., and Hamilton-Mackenzie, J. (2010) "Retaining a foothold on the slippery paths of academia: university women, indirect discrimination and the academic marketplace." Gender and Education 22(5): 535-545.

Winnicott, D. (1971, 2005) Playing and Reality. Abingdon, Oxon: Routledge.

Woodyatt, C.R., Finneran, C.A., and Stephenson, R (2016) “In-person versus online focus group discussion." Qualitative Health Research, 26(6): 741-749.

Wright, L.A., Schwindt, L.A., Bassford, T.L., Reyna, V.F., Shisslak, CM, St

Germain, P.A., and Reed, K.L. 2003. "Gender differences in academic advancement: Patterns, causes, and potential solutions in one U.S. College of Medicine." Academic Medicine, 78(5): 500-508.

\section{Acknowledgements}

We would like to acknowledge Bournemouth University for awarding the authors the 
Gender and Education

research funding that enabled this study to be undertaken. 